\title{
Manipulation of the tuf gene provides clues to the localization of sequence element(s) involved in the thermal stability of Thermotoga maritima elongation factor Tu
}

\author{
Anna M. Sanangelantoni, ${ }^{1}$ Piero Cammarano ${ }^{2}$ and Orsola Tiboni ${ }^{1} \dagger$
}

Author for cortespondence: Anna M. Sanangelantoni. Tel: +39382 505578. Fax: +39 382528496. e-mail: Sanan@ipvgen.unipv.it

1 Dipartimento di Genetica e Microbiologia 'A. Buzzati

Traverso', Università di Pavia, via Abbiategrasso 207, 27100 Pavia, Italy

2 Istituto PasteurFondazione Cenci Bolognetti, Dipartimento Biopatologia Umana, Sezione Biologia Cellulare, Policlinico Umberto I Università di Roma 'La Sapienza', 00161 Roma, Italy
Truncated versions of the tuf gene for elongation factor Tu (EF-Tu; 400 aa) from the hyperthermophilic bacterium Thermotoga maritima have been produced by progressive $3^{\prime} \rightarrow 5^{\prime}$ trimming. The truncated genes have been expressed in Escherichia coli and the thermal stability of the gene products has been assayed by monitoring their GDP-binding capacity after preheating the cell-free extracts at various temperatures $\left(65-95^{\circ} \mathrm{C}\right)$. One of the truncated proteins, corresponding to the nucleotide-binding domain (G domain; aa 1-200) appears to be only slightly less stable than the full-length EF-Tu. Replacement of the first $\mathbf{9 0} \mathbf{N}$-terminal residues of both the full-length Thermotoga EF-Tu and the isolated $G$ domain with the corresponding sequence of the mesophilic bacterium $E$. coli, drastically destabilizes both the complete and the truncated protein, indicating that sequence element(s) that are crucial for the attainment of a thermally stable conformation of the Thermotoga EFTu lie well within the initial portion of the $G$ domain between residues 1 and 90. The relevant residues defy identification, however, as no amino acid preferences, or exclusive sequence element(s), appear to distinguish the $\mathbf{N}$ terminal region of the thermophilic proteins from those of mesophilic counterparts. It is suggested that the thermal stability of Thermotoga EF-Tu is critically dependent upon unique tertiary structural interactions involving certain $\mathbf{N}$-terminal residues of the molecule.

Keywords: elongation factor $\mathrm{Tu}$, extreme thermophiles, thermostability, protein engineering, genetic manipulation

\section{INTRODUCTION}

Proteins from hyperthermophilic micro-organisms maintain their heat tesistance upon expression in mesophilic hosts (Love \& Streiff, 1987; Tiboni et al., 1989; Sanangelantoni et al., 1992), indicating that heat stability is solely due to intrinsic features of the molecule rather than to extrinsic factors (Fabry et al., 1989; Schultes et al., 1990). Nonetheless, no unique amino acid substitution scheme, or exclusive sequence motif, distinguishes the thermophile proteins from their mesophile counterparts (Adams, 1993). This implies that thermal resistance may be brought about by subtle (and elusive) primary structural changes resulting in increased hydrophobicity, chain tigidity and

- Deceased. overall tightness of intramolecular packing (Nosoh \& Sekiguchi, 1990). However, evidence for this is scanty.

The elongation factors ubiquitously involved in aminoacyl-tRNA binding to ribosomes (EF-Tu for Bacteria; EF-1a for Archaea and Eucarya) offer a good case in protein stability studies. First, the available sequences (about 400 relatively conserved residues) span a host of evolutionarily diverse organisms including the hyperthermophilic bacterium Thermotoga maritima (Bachleitner et al., 1989) and an as yet unpublished sequence of Aquifex pyrophilus (W. Ludwig, Technische Unversität München, Germany, personal communication). Secondly, the stability difference between the $T$. maritima factor, which withstands temperatures up to $9095^{\circ} \mathrm{C}$, and that of the mesophile $E$. coli, which is inactivated at temperatures slightly above $50^{\circ} \mathrm{C}$, is far greater than that seen for most other proteins. Thirdly, the T. maritima gene for EF-Tu 
$(t u f)$ can be overexpressed in E. coli and the heterologous gene product can be easily purified via the selective denaturation of the (heat-labile) host-cell proteins (Tiboni et al., 1989). Lastly, the EF-Tu N-terminal domain involved in GTP binding and hydrolysis (about 200 residues) retains its GTP-binding capacity following removal of the middle and $\mathrm{C}$-terminal domains involved in the binding of aminoacyl-tRNA, elongation factor Ts and kirromycin-like antibiotics (Weijland $e t a l ., 1992$ ). In principle this enables one to selectively modify tuf regions corresponding to individual EF-Tu domains and to assess the stability of the encoded protein by means of simple functional assays. This approach may thus allow the localization of sequence element(s) that are responsible for the increased overall stability of the thermophile protein.

In this report, truncated versions of the $T$. maritima $\mathrm{EF}$ $\mathrm{Tu}$, and chimeric (mesophile/thermophile) versions of both the full-length protein and the $G$ domain, have been generated by manipulation of the tuf gene; the modified gene sequences have been expressed in $E$. coli and the thermal stability of the gene products has been monitored by means of GDP-binding assays. The results suggest that sequence element $(\mathrm{s})$ located in the $\mathrm{N}$-terminal portion of the $G$ domain play a crucial role in maintaining the thermally stable conformation of the T. maritima protein, although no distinguishing primary structural features can be identified through comparison of thermophile and mesophile EF-'Tus.

\section{METHODS}

Bacterial strains and plasmids. Plasmids pTM6 (Tiboni et al., 1989 ) and $A B 80$ (Bernardi \& Bernardi, 1979), containing the tuf genes of $T$. maritima and $E$. coli, respectively, were used to prepare the truncated and chimeric genes. Plasmids pDR720 (Russel \& Bennet, 1982), pBR322 (Bolivar et al., 1977) and pUC19 (Vieira \& Messing, 1982) were used as the vectors and E. coli $\mathrm{HB} 101$ as the host. Plasmid-containing strains were grown either in LB medium or in M9 medium supplemented with $50 \mu \mathrm{g}$ ampicillin $\mathrm{ml}^{-1}$.

Recombinant DNA techniques. Plasmid DNA was isolated and purified using Qiagen tips following the procedures suggested by the supplier (Diagen). Recovery of DNA fragments from low-meiting-point agarose gels was performed according to Higuchi et al. (1981). Transformation experiments were cartied out as described by Dagert \& Ehrlich (1979). Truncated tuf genes were obtained using the progressive deletion system 'Erase-a-Base' (Promega) following the manufacturer's instructions. 'The $3^{\prime}$ end of the inserts cloned in pUC19 was sequenced by the dideoxynucleotide chain-termination method of Sanger et al. (1977). DNA was radiolabelled with $\left[\alpha^{-35} \mathrm{~S}\right] \mathrm{dATP} \alpha \mathrm{S}$ (Amersham; sp. act. $>37 \mathrm{TBq} \mathrm{mmol}^{-1}$ ) and primed as specified by the manufacturer using a T7 sequencing kit (Pharmacia).

Plasmid constructions. The recombinant plasmid pTM6 was digested with $S_{a l}$. The DNA fragment of $1905 \mathrm{bp}$, containing the entire tuf gene and the $3^{\prime}$ end of the fus gene, encoding the elongation factor $G$, was recovered from low-melting-point aga rose gel and ligated into the unique $S_{a} l$ I site of the expression vector $\mathrm{PDR} 720$ under the control of the inducible trp promoter. The T. maritima insert, together with the inducible trp promoter, was then transferred to the EcoRI site of PUC19 and the plasmid p'Tu1 was obtained (see Fig. 3). The control plasmid pTu6, containing the trp promoter and the $3^{\prime}$ end of the fus gene, was derived from plasmid pTu1 by complete deletion of the EF-Tucoding sequence using the 'Erase-a-Base' system. This plasmid was also used as the vector to construct the recombinant plasmid $\mathrm{pTuB}$. The $\mathrm{pTuB}$ plasmid, harbouring the E. coli tufB gene under the $\operatorname{tr} p$ promoter, was produced by EcoRV digestion of the recombinant plasmid $\mathrm{AB} 80$ followed by cloning of the insert (about $3500 \mathrm{bp}$ ) into in the EcoRV site of pBR322. From this plasmid, the $t u f B$ gene was first subcloned in pUC19, and then excised by digestion with $B a m \mathrm{HI}$ and $S p h \mathrm{I}$ (pUC19 polylinker sites) and inserted in the control plasmid p'Tu6 digested with the same restriction enzymes (see Fig. 3).

Induction of transformed $\boldsymbol{E}$. coli cells. E. coli HB101 cells harbouring plasmids containing either the $T$. maritima tuf gene, or the manipulated genes, were grown at $37^{\circ} \mathrm{C}$ to $\mathrm{OD}_{650} 0.5$ in M9 salt medium supplemented with $1.0 \mathrm{mM}$ magnesium sulphate, $0 \cdot 2 \%$ glucose and $0.3 \%$ Casamino acids; 3 - $\beta$-indoleacrylic acid was then added to a concentration of $5.0 \mu \mathrm{g} \mathrm{ml}^{-1}$ and the incubation was continued for a further $2.5 \mathrm{~h}$. Cells were collected by centrifugation at $5000 \mathrm{~g}$ for $10 \mathrm{~min}$ and washed with buffer A ( $50 \mathrm{mM}$ 'Tris/ $\mathrm{HCl}, \mathrm{pH} 8.0,10 \mathrm{mM} \mathrm{MgCl}_{2}, 50 \mathrm{mM}$ $\mathrm{KCl}, 7.0 \mathrm{mM} 2$-mercaptoethanol) and stored at $-20^{\circ} \mathrm{C}$ until use.

Preparation of cell-free extracts and GDP-binding assays. Cells were broken by grinding with twice their own mass of alumina powder. The paste was extracted with buffer A $(3-0 \mathrm{ml}$ per $\mathrm{g}$ wet cells). After centrifugation at $30000 \mathrm{~g}$ for $30 \mathrm{~min}$ to remove alumina and cell debris, the clear extracts were centrifuged at $100000 \mathrm{~g}$ for $2 \mathrm{~h}$ and $100 \mu \mathrm{l}$ aliquots of the resultant ribosome-free supernatant ( $\$ 100$, containing 8-12 mg protein $\mathrm{ml}^{-1}$, depending on the preparation), were incubated for $10 \mathrm{~min}$ at vatious temperatures between $65^{\circ} \mathrm{C}$ and $95^{\circ} \mathrm{C}$. As noted elsewhere (Tiboni et al., 1989), a preliminary $10 \mathrm{~min}$ incubation of the $\mathrm{S} 100$ at $65^{\circ} \mathrm{C}$ is essential for the activation of the T. maritima EF-Tu expressed by transformed E. coli cells and for denaturation of most E. coli host-cell proteins.

After removal of precipitated proteins (10 min centrifugation at $10000 \mathrm{~g}$ ) the GDP-binding activity was assayed by measuring the amount of $\left[{ }^{3} \mathrm{H}\right] \mathrm{GDP}$ (Amersham; sp. act. $459 \mathrm{GBq} \mathrm{mmol}^{-1}$ ) bound by $10 \mu \mathrm{l}$ of the heat-treated extracts, during a $10 \mathrm{~min}$ incubation at 30 or $65^{\circ} \mathrm{C}$ (Tiboni et al., 1978).

Separation of chimeric $\mathbf{G}$ domain. All operations were carried out at $4^{\circ} \mathrm{C}$. Cell-free extracts from $15 \mathrm{~g}$ of cells were prepared in buffer B (50 mM Tris/HCl, pH 7.4, $10 \mathrm{mM} \mathrm{MgCl}_{2}, 80 \mathrm{mM} \mathrm{KCl}$, $7.0 \mathrm{mM} 2$-mercaptoethanol, $15 \%, \mathrm{v} / \mathrm{v}$, glycerol) as described previously. The protein solution $(35 \mathrm{ml})$ was applied to a $2.5 \times 35 \mathrm{~cm}$ DEAE-cellulose DE52 column equilibrated with buffer B. After adsorption of the sample, the column was developed with $1180-320 \mathrm{mM} \mathrm{KCl}$ gradient in buffer $\mathrm{B}$ at a constant flow rate of $50 \mathrm{ml} \mathrm{h}^{-1}$ while collecting fractions of $12 \mathrm{ml}$. Fractions were assayed for GDP-binding activity at $30^{\circ} \mathrm{C}$ and the protein profile was determined by SDS-PAGE. Positive fractions were pooled, dialysed against buffer $B$ without glycerol, and solid ammonium sulphate was added to $75 \%$ saturation. After centrifugation at $20000 \mathrm{~g}$ for $15 \mathrm{~min}$ the protein precipitate was dissolved in buffer $B$ containing $10 \mathrm{mM}$ GDP.

PAGE. Proteins were analysed by SDS-PAGE (Laemmli, 1970). The following markers were used: lysozyme $(14.4 \mathrm{kDa})$, soybean trypsin inhibitor $(21.5 \mathrm{kDa})$, carbonic anhydrase $(31 \mathrm{kDa})$, ovalbumin (45 kDa), BSA $(66.2 \mathrm{kDa})$ and phosphorylase $\mathrm{b}$ (92.5 kDa). Proteins were stained with Coomassie brilliant blue.

Sequence analysis. Analysis of the DNA sequence was performed using the DNA STRIDER 1.0 program (Marck, 1988). 
EF-Tu homologous sequences were retrieved from the databases using the BLAST program (Altschul et al., 1990) through the Human Genome Mapping Project (HGMP) facility, Cambridge, LK. Multiple alignments were obtained using the CLUSTAL $W(1.4)$ program in the GCG software package.

\section{RESULTS AND DISCUSSION}

The T. maritima EF-Tu sequence was aligned with all of the bacteriai and archaeal sequences presently available in the databanks, and with an as yet unpublished EF-Tu sequence from the hyperthermophilic bacterium Aquifex pyropbilus (courtesy of W. Ludwig) probably representing the deepest known branching in the bacterial tree (Burggraf et al., 1992; Bocchetta et al., 1995). For concision of presentation only two mesophilic and two thermophilic sequences are shown in Fig. 1 (a global alignment of the T. maritima and Thermus EF-Tus with all mesophilic counterparts is available from the authors upon request). All of the bacterial sequences appear to be highly conserved $(65 \cdot 2-86 \cdot 8 \%$ overall sequence identity), especially within the $\mathrm{N}$-terminal region harbouring the three consensus elements (GXXXXGK, DXXG and NKXD; underlined in Fig. 1) that are involved in the formation of the GTP-binding pocket (Dever et al., 1987). Unlike the situation with other thermophile proteins (Argos et al., 1979; Fabry et al., 1989; Schultes et al., 1990) analysis of the thermophile EF-Tu sequences showed no

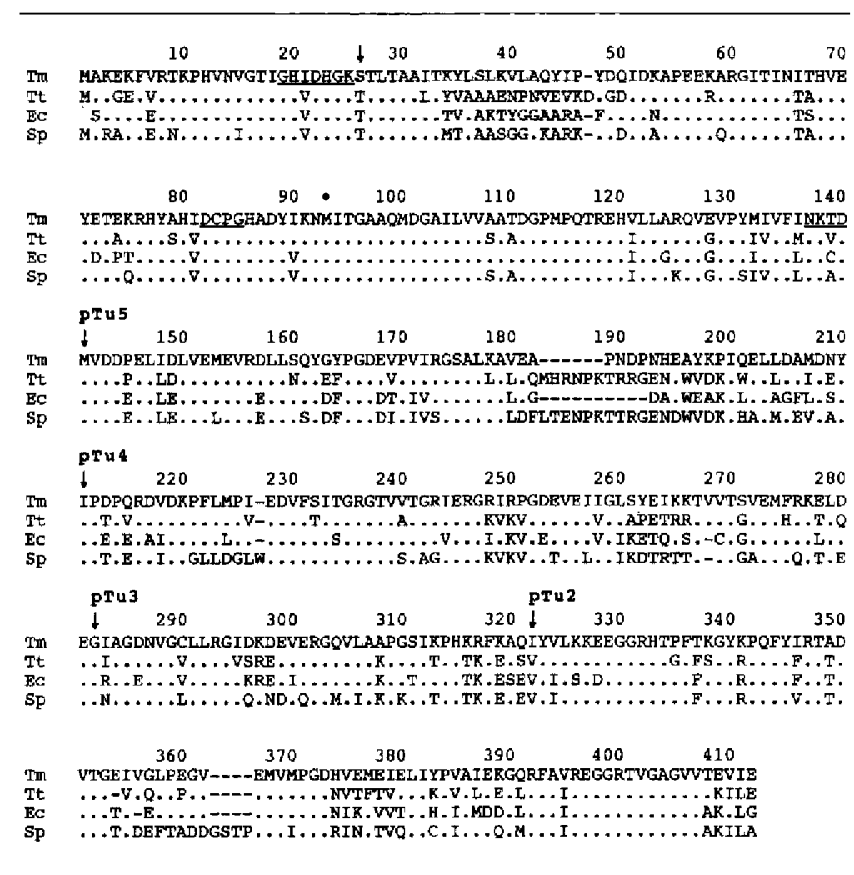

Fig. 1. Alignment of the T. maritima (Tm) EF-Tu amino acid sequence with the sequences of EF-Tu from: Tt, Thermus thermophilus (Seidler et al., 1987); EC, E. coli ; and Sp, Spirulina platensis (Buttarelli et al., 1989). The three consensus elements are underlined. The amino acid sequence of the products of progressively deleted genes is indicated by an arrow on the last amino acid. A vertical arrow also indicates the $S$ residue present in both the Thermotoga and Aquifex sequences. An asterisk indicates the position of the Bc/l site. Residues identical to the Thermotoga sequence are indicated by dots. obvious trend towards replacement of small amino acids with bulkier and more hydrophobic ones; also, careful inspection of alignment positions failed to reveal primary structural elements exclusive to the three thermophile sequences. Furthermore, amino acids shared only by the two hyperthermophilic sequences (T. maritima and Aqui$f e x)$ were detected at a limited number of sites. Nevertheless, their involvement in thermal resistance can be ruled out by comparison with the corresponding archaeal sequences. For instance, a ' $T$ to $S$ substitution at position 26 of the alignment (indicated by a vertical arrow in Fig. 1 ) is found in both the T. maritima and the Aquifex sequences; its importance for the thermal stability of the two (eu)bacterial EF-Tus is dubious, however, as an $\mathrm{S}$ residue at the corresponding sequence position is evident in all of the available archaeal sequences (from both mesophilic and thermophilic sources). This prevented site-directed mutagenesis experiments aimed at identifying single residues that could be responsible for the high stability of the thermophile protein. Consequently, the sequence element(s) involved in the thermal stability of $T$. maritima $\mathrm{EF}_{-} \mathrm{Tu}$ were investigated by constructing progressively deleted, or chimeric, $t u f$ genes, and testing the heat resistance of the resultant gene products.

Inspection of the restriction map of the plasmid p'Tu1, containing the $T$. maritima tuf gene, revealed a unique $B g / I I$ site situated 263 bp upstream from the termination codon of tuf, which created ends compatible with those produced by the BamHI site of the pUC19 polylinker. Accordingly, a first deletion clone (termed P'Tu2) was produced by digestion of pTu1 with restriction enzymes $B g / I I$ and BamHI followed by ligation (Fig. 1). Additional progressive deletions were produced by the "Erase-aBase' system starting from a $B g / \mathrm{II} / K p n I$-digested pTu1 plasmid. The resultant recombinant plasmids were analysed for insert length and only inserts having a suitable size were sequenced at the $3^{\prime}$ end. Clones having a termination codon immediately downstream of the $T$. maritima tuf sequence, namely p'Tu3, p'Tu4, p'Tu5 (whose encoded polypeptide is indicated by an arrow on the last amino acid in the alignment shown in Fig. 1) and pTu6 (in which the entire tuf gene had been deleted), were selected for further analysis.

\section{Expression of the truncated genes and thermal stability of the gene products}

As Fig. 1 shows, all of the polypeptides encoded by the truncated tuf genes contain the three consensus elements required to form the nucleotide-binding pocket. Therefore, the presence of the expressed proteins could be monitored by measuring the GDP-binding capacity of the cell-free extracts at $65^{\circ} \mathrm{C}$, a temperature treatment that allows offsetting of host-cell EF-Tu activity and is also required to activate the entire (overexpressed) $T$. maritima EF-Tu (Tiboni et al., 1989). In essence, cell-free extracts were prepared from E. coli HB101 cells transformed with plasmids harbouring the entire $T$. maritima tuf gene (plasmid pTu1), or the progressively deleted versions thereof (plasmids pTu2 to pTu5), and comparable extracts 
(a)
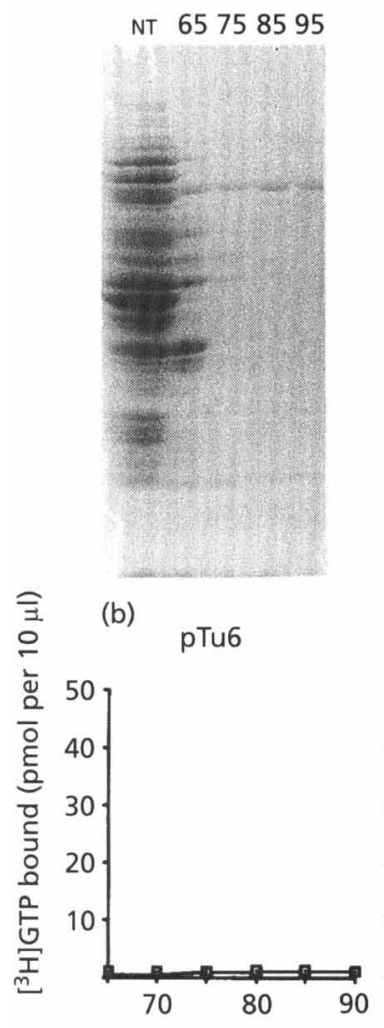

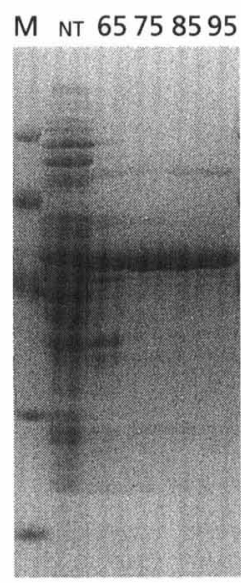

pTu1

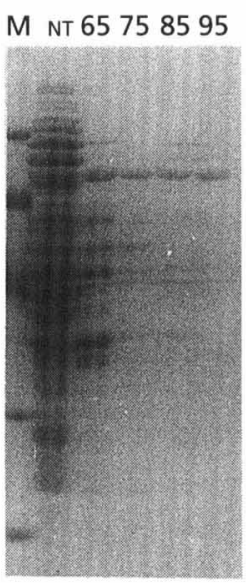

pTu2
M NT 65758595

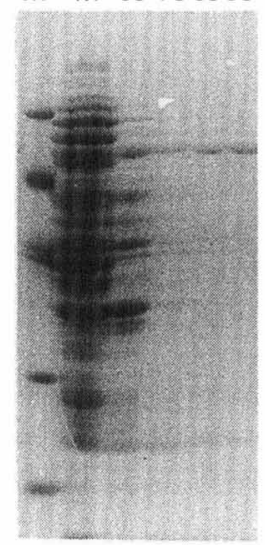

pTu3
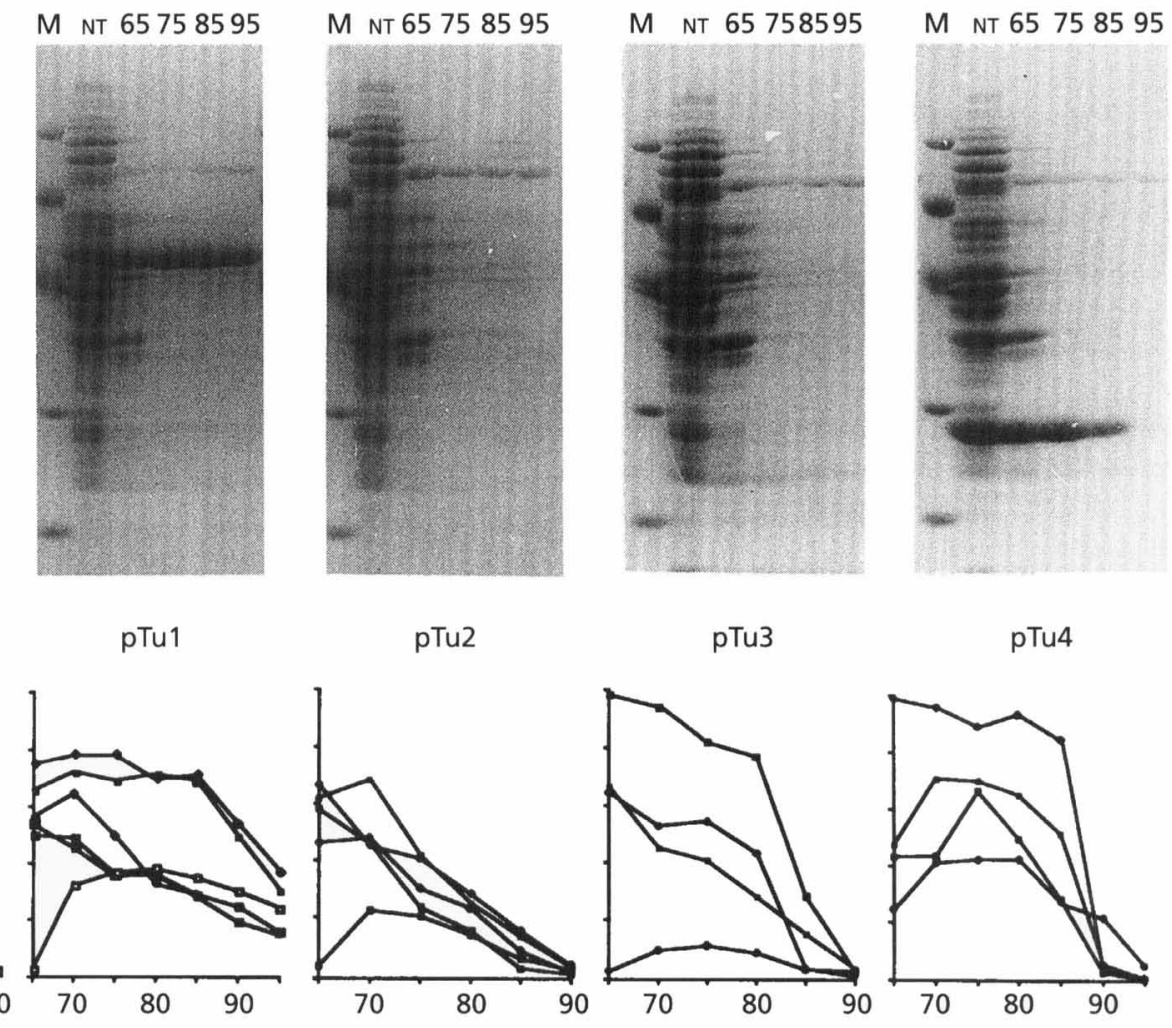

Pre-treatment temperature $\left({ }^{\circ} \mathrm{C}\right)$

Fig. 2. Expression in E. coli of progressively deleted Thermotoga tuf genes. (a) SDS-PAGE analysis on $10 \mu l$ aliquots of the extracts of $E$. coli transformed with the following plasmids: pTu6 (control), pTu1 (harbouring the gene encoding the $T$. maritima EF-Tu), pTu2, pTu3 and pTu4 (encoding the isolated G domain), heated at the indicated temperatures $\left({ }^{\circ} \mathrm{C}\right.$ ). NT, Not treated. The gel electrophoretic patterns are representative of all \$100 preparations obtained. Identical gel patterns and similar proportions of heterologous proteins were observed in different preparations irrespective of differences in the GDP-binding capacity (see b). Lane $\mathrm{M}$ contains molecular mass markers. GDP-binding activity of extracts treated and assayed as reported in Methods (7500 c.p.m. correspond to 1 pmol of bound GDP). Note that in the pTu1 and pTu4 assays the maximum preincubation temperature was $95^{\circ} \mathrm{C}$ instead of $90^{\circ} \mathrm{C}$. The results of four to six separate assays are shown.

were also prepared from cells containing the control plasmid pTu6. In preliminary assays, all extracts, except those derived from cells containing plasmids pTu5 and pTu6, were found to exhibit an appreciable GDP-binding capacity following incubation at $65^{\circ} \mathrm{C}$ (data not shown). As the pTu5-encoded protein (Fig. 1) still contains the three consensus elements that are required to form the nucleotide-binding pocket, but lacks GDP-binding activity, the minimum EF-Tu sequence required for GTP/ GDP binding is borne by plasmid pTu4. By compatison with the E. coli sequence (An \& Friesen, 1980; Yokota et al., 1980), the polypeptide encoded by the latter plasmid was found to correspond to the EF-Tu G domain (residues 1-200) (Parmeggiani et al., 1987). Importantly, extracts from $E$. coli cells harbouring the pTu6 plasmid were completely devoid of GDP-binding activity at $65^{\circ} \mathrm{C}$, as expected if E. coli EF-Tu is completely denatured at this temperature.

In order to investigate the heat stability of the truncated EF-Tu proteins, aliquots of the S100 fraction (see Methods) were incubated at various temperatures be- tween $65^{\circ} \mathrm{C}$ (the temperature required for activation of overexpressed T. maritima EF-Tu) and $95^{\circ} \mathrm{C}$; the GDPbinding capacity of the preheated samples was then assayed at a constant temperature of $65^{\circ} \mathrm{C}$.

The gel electrophoretic patterns in Fig. 2(a) show that the products of the four recombinant plasmids a re expressed to different degrees. Namely, the gel patterns of heattreated S100 from E. coli cells harbouring either the pTu1 or the pTu4 plasmids display a prominent extra band that resists heating at $95^{\circ} \mathrm{C}$ (pTu1) and $85^{\circ} \mathrm{C}$ (p Tu4). Although no extra bands are discernible in extracts prepared from cells harbouring either pTu2 or pTu3, the production of heterologous ( $T$. maritima), thermally stable, protein by the two latter clones can still be inferred by the GDP-binding capacity of the extracts (Fig. 2b).

The results of GDP-binding assays carried out using several independent S100 preparations of each of the four recombinant clones are shown in Fig. 2(b). Variations in the GDP-binding capacity of the different preparations obtained from the same recombinant clone are probably accounted for by different activation levels attained by the 

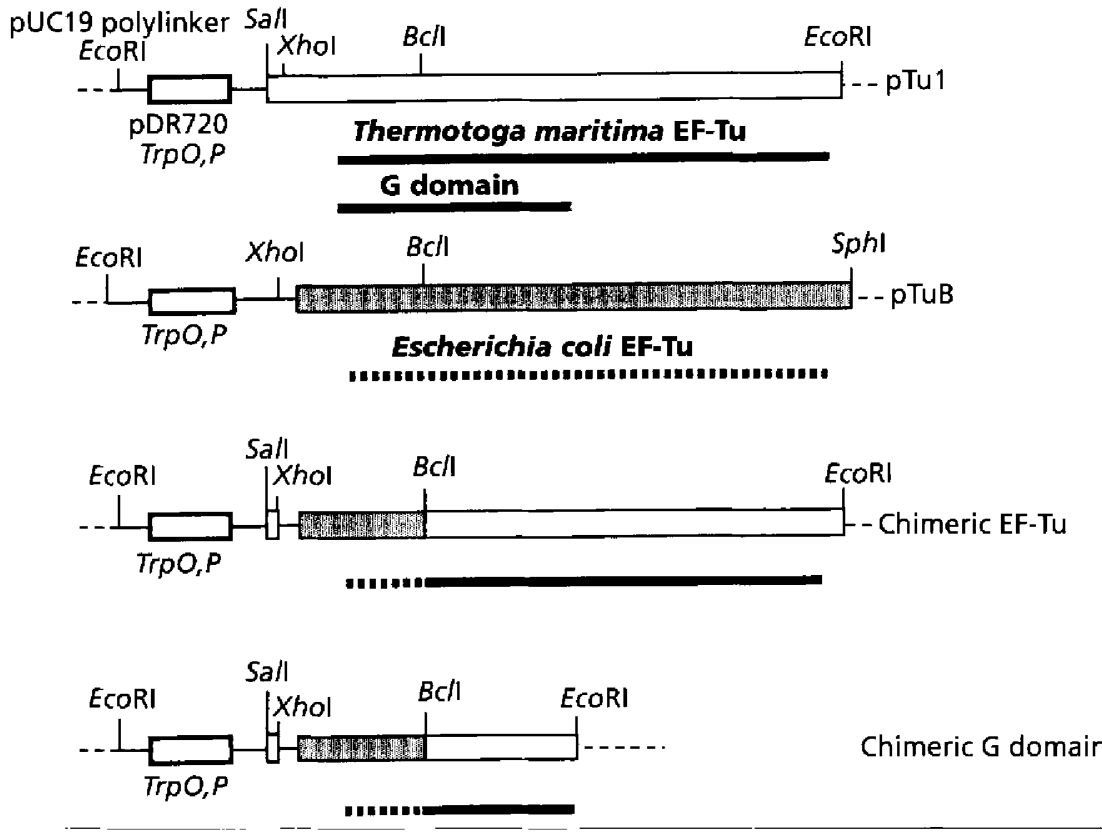

Fig. 3. Diagram of the genes encoding the parental and chimeric EF-Tu and G domain. Only the relevant restriction sites are indicated. Solid and dashed lines below the genes represent the encoded products. recombinant proteins during preheating and, to a minor extent, by differences in protein content of the parent cellfree extracts (8-12 $\mu \mathrm{g}$ protein $\mu^{-1}$ ) (see Methods) or by different expression levels of the heterologous protein. Despite differences in the activity levels, however, independent preparations obtained from the same parent clone exhibit similar thermal-inactivation profiles. Indeed, the pTul-encoded protein (full-length FF-Tu) is still apparent in the gel electrophoretic patterns of extracts heated up to $95^{\circ} \mathrm{C}$ (Fig. $2 \mathrm{a}$ ) and its GDP-binding activity is not abolished following heating (Fig. 2b).

The plots in Fig. 2(b) also show that the plasmid pTu2encoded protein (aa 1-316), which lacks the last $86 \mathrm{C}$ terminal residues of the EF-Tu appears to be less heat stable than the full-length protein: its activity is completely abolished by heating at $90^{\circ} \mathrm{C}$ and greatly reduced by heating at $85^{\circ} \mathrm{C}$ (as deduced by GDP-binding assays). No further reduction of the protein's stability occurs upon removal of 40 additional residues (plasmid p'Tu3, aa 1-276). Also, no further decrease in thermal stability is observed by extending deletions up to clone pTu4 which encodes the $T$. maritima $G$ domain. In fact, the isolated $G$ domain (aa 1-206) seems to be more heat stable than the pTu2- and pTu3-encoded proteins, although somewhat less stable than the full-length EF-Tu. This latter point is inferred by the fact that the protein is still abundant following heating of the extracts at $85^{\circ} \mathrm{C}$, but totally absent following heating at $95^{\circ} \mathrm{C}$.

The different stabilities of the three truncated proteins can be interpreted on the basis of the known three-dimensional structure of E. coli EF-Tu (Kjeldgaard \& Nyborg, 1992). This appears to comprise three domains [a 1-200 (G domain), aa 209-299 (domain 11 ) and aa 300-393 (domain III)] whose interactions are important for the global function of the protein, and its overall structure is basically conserved in the thermophilic bacterium Thermus thermophilus (Berchtold et al., 1993). Although the native EF-Tu is required for tRNA binding to ribosomes, the three isolated domains do possess some of the EF-Tu activities. Namely, the $E$. coli $G$ domain prepared using a genetically engineered tuf $A$ (Parmeggiani et al., 1987) has been shown to retain certain properties of the intact molecule such as GDP and GTP-binding capacity and to display an intrinsic GTPase activity. Domain II/III (middle and C-terminal domains), isolated as a single polypeptide by tryptic digestion of the Tbermus thermophilus EF-Tu, has been shown to maintain the ability to bind the elongation factor ' $T$ s and to be essentially refractory to proteolytic attack (Peter et al., 1990). As the isolated domains, although stable, are more prone to thermal denaturation than the intact protein, it seems that the ability of the thermophile EF-Tu to withstand temperatures up to $95^{\circ} \mathrm{C}$ rests not only on specific amino acid preferences, but also on stabilizing co-operative interactions between the three domains. As the truncated Thermotoga maritima EF-Tus encoded by plasmids pTu2 and pTu3 lack either a segment of domain III (pTu2), or the entire domain III and part of domain II (pTu3), they are probably unable to attain the correct tertiary folding and, for this reason, they are more susceptible to thermal denaturation. In addition, as all the $t u f$ genes possess an identical upstream region comprising promoter and ribosome binding sitc, the low expression levels of the recombinant protein in cells harbouring plasmids pTu2 and pTu 3 can be accounted for by degradation of the gene products by proteases of the mesophile host. If this is the case, the relative abundance of $T$. maritima $G$ domain in $E$. coli cells harbouring the pTu4 plasmid could reflect a more compact tertiary packing, rendering the protein less susceptible to proteolytic attack.

As expected, no GDP-binding activity, and no extra bands, are discernible in $\mathrm{S} 100$ extracts prepared from $E$. coli cells containing the control plasmid p Tu6 (Fig. 2a, b). 

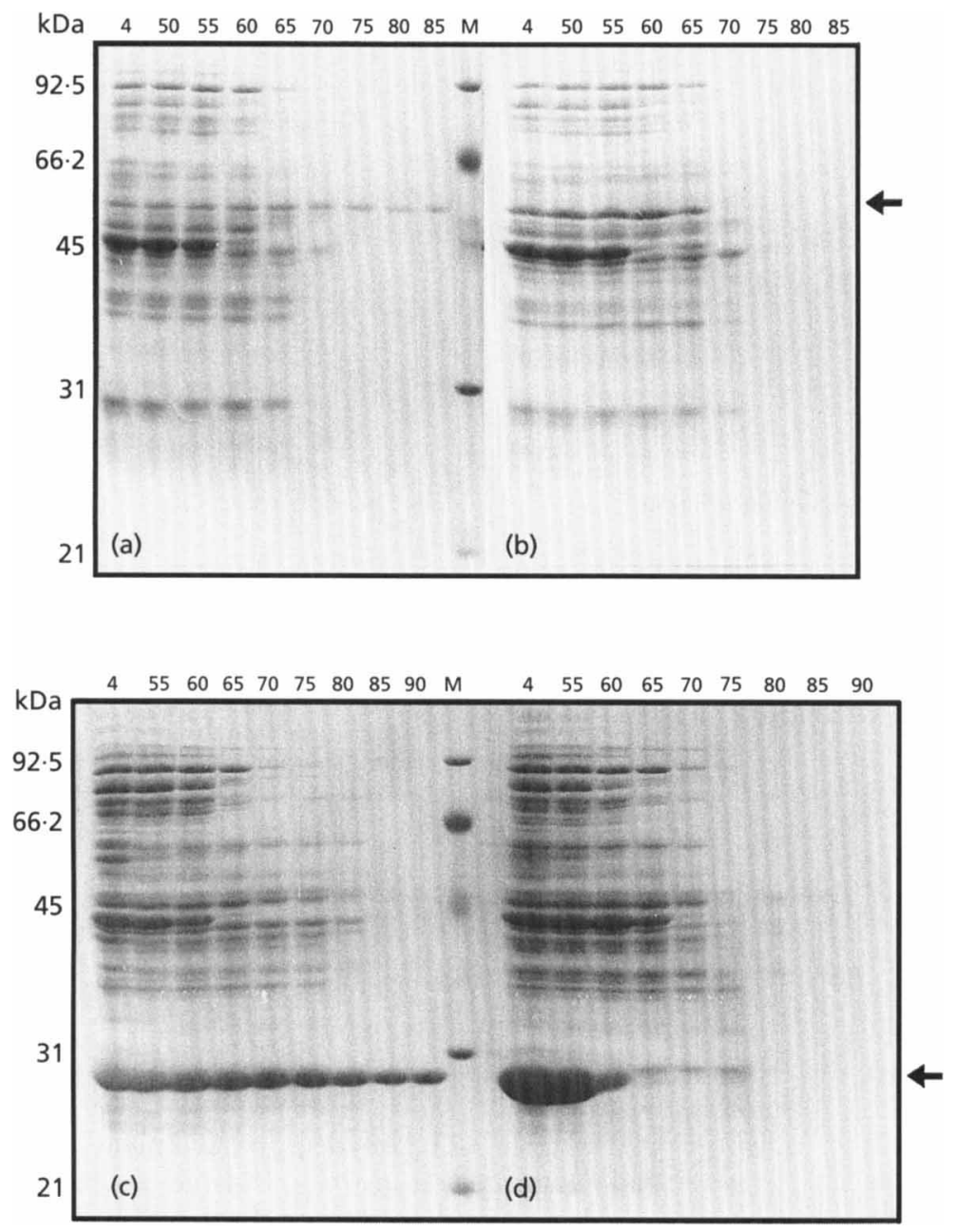

Fig. 4. SDS-PAGE of the parental ( $T$. maritima) and chimeric ( $T$. maritima/E. coli) proteins expressed in $E$. coli. Extracts from $E$. coli cells transformed with plasmids (a) pTu1: (b) plasmid harbouring the chimeric tuf gene; (c) pTu4; and (d) plasmid harbouring the chimeric $G$ domain gene. Samples were treated as reported in Fig. 2. Arrows indicate the position of the expressed proteins. Lane $M$ contains molecular mass standards.

\section{Construction of chimeric tuf genes and analysis of the encoded products}

Since a unique $B c l \mathrm{l}$ site lies at an identical position (nucleotide 273) in both the T. maritima (Bachleitner $t$ t al., 1989) and the E. coli (An \& Friesen, 1980; Yokota et al., 1980) tuf gene sequences, hybrid genes were constructed to assess the contribution of the first 90 amino acids to the heat stability of both the $T$. maritima EF-Tu and the isolated $\mathrm{G}$ domain. To this end, the recombinant plasmids pTu1, pTu4 and pTuB (harbouring the E. coli tufB gene) were digested with $X b_{o} \mathrm{I}$ and $B c l \mathrm{I}$ and the resultant fragments were ligated to generate the chimeras shown in Fig. 3.

SDS-PAGE analysis of crude extracts obtained from $E$. coli cells transformed with recombinant plasmids encoding a chimeric EF-Tu, or a chimeric $\mathrm{G}$ domain, displayed an extra band of molecular mass about 48 or $30 \mathrm{kDa}$, respectively (Fig. 4b, d). Incubation of the extracts at increasing temperatures (up to $85-90{ }^{\circ} \mathrm{C}$ ) showed that replacement of the N-terminal portion (90 aa) of the thermophile proteins with the corresponding portion of their mesophile (E. coll) counterpart does affect the protein's thermal stability. As Fig. 4(a,b) shows, while the protein band (arrow in Fig. 4) corresponding to the $T$. maritima EF-Tu tolerates heating at $85^{\circ} \mathrm{C}$, the chimeric protein begins to disappear following incubation of the extracts at $70^{\circ} \mathrm{C}$. Therefore, this region of the $T$. maritima EF-Tu harbours sequence element(s) which are essential for the maintenance of its thermally stable conformation. When the same analysis was extended to the $G$ domain (Fig. 4c, d), which lacks the co-operative interactions with domains II and III, the effect of temperature on protein stability was more dramatic, the chimeric protein being as heat labile as the mesophile EF-Tu.

The authenticity of the chimeric EF-Tu was confirmed by testing the ability of cell-free extracts to bind GDP at $65^{\circ} \mathrm{C}$ (data not shown). The same experiment was not feasible in the case of the chimeric $G$ domain, as the protein was completely inactivated at $65^{\circ} \mathrm{C}$ and a GDPbinding assay done below this temperature did not allow discrimination of the chimetic $G$ domain and the host EF$\mathrm{Tu}$ activities. Accordingly, separation of this chimeric protein from the E. coli EF-Tu was undertaken.

Extracts prepared from E. coli cells harbouring the recombinant plasmid encoding the chimeric $G$ domain were chromatographed on a DEAE-cellulose column and the fractions were tested for GDP-binding activity at $30{ }^{\circ} \mathrm{C}$. As Fig. 5 shows, two activity peaks were detected and identified as the E. coli EF-Tu and the chimeric G domain, respectively, on the basis of their SDS-PAGE 

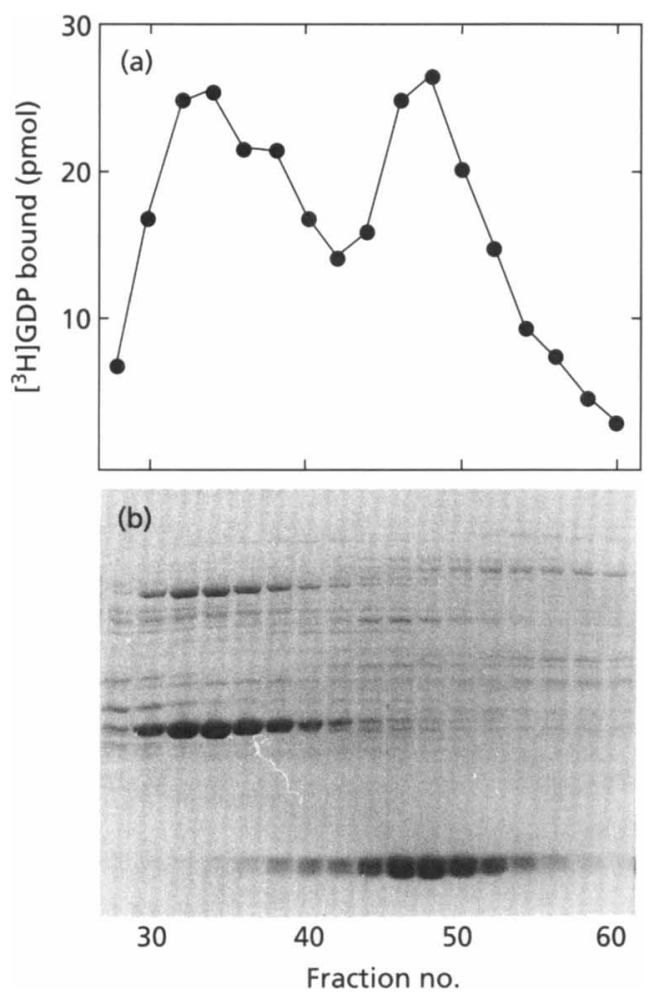

Fig. 5. DEAE-cellulose chromatography of extracts prepared from $E$. coli cells transformed with the plasmid bearing the chimeric $G$ domain sequence. (a) GDP-binding activity of the eluted fractions assayed at $30^{\circ} \mathrm{C}$ on $10 \mu$ aliquots; (b) SDSPAGE analysis of $10 \mu \mathrm{l}$ aliquots of the same samples.

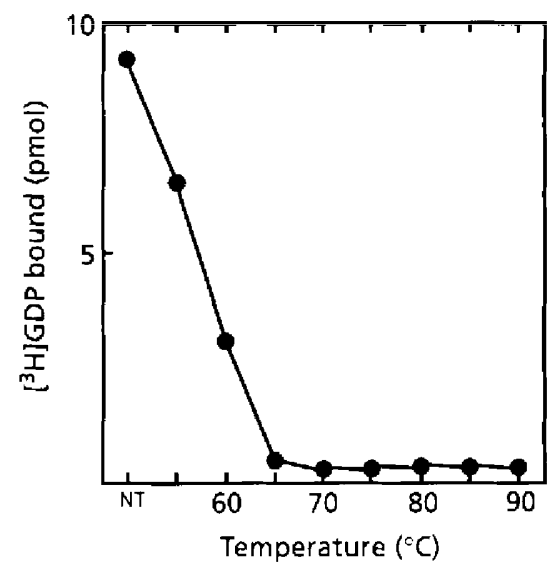

Fig. 6. Effect of preincubation at increasing temperatures on the GDP-binding capacity of the partially purified chimeric G domain. The samples were treated as described in Fig. 2 and the GDP-binding activity was assayed at $30^{\circ} \mathrm{C}$. NT, Not treated.

mobility. The partially purified chimcric (; domain was then incubated at increasing temperatures (betwcen 45 and $90^{\circ} \mathrm{C}$ ). As Fig. 6 shows, the GDP-binding activity of the chimeric protein was drastically reduced following incubation at $60^{\circ} \mathrm{C}$ and disappeared altogether upon incubation at $65^{\circ} \mathrm{C}$ in accordance with the gel electrophoretic patterns of crude extracts in Fig. 4(d).
On the whole, the results in Fig. 4 indicate that the thermal stability of both the thermophilic EF-Tu and the $\mathrm{G}$ domain are crucially dependent upon residues situated in the N-terminal region of the molecule, within the first half of the $G$ domain. However, we have found that replacement of the first 90 residues of the mesophile ( $E$. coli) EF-Tu with the corresponding region of the $T$. maritima protein does not result in increased heat stability (data not shown). We interpret this result as indicating that the remarkable heat resistance of the T. maritima $\mathrm{EF}-$ $\mathrm{Tu}$ is critically dependent upon unique tertiary structural interactions between certain $\mathrm{N}$-terminal residues and distal residues that are absent in the E. coli moiety of the hybrid protein.

\section{Conclusions}

Primary structural comparison and engineering of the tuf gene sequence of the thermophile T. maritima allow the following conclusions. (1) Interactions between the three domains constituting the native EF-Tu play a role in maintaining the heat stability of the molecule. This is supported by the evidence that the isolated $G$ domain of T. maritima EF-Tu is slightly less stable than the fulllength protein, in accordance with the situation in E. coli (Jensen et al., 1989). (2) Sequence elcment's) that are crucial for heat stability appear to lie within the Nterminal portion of the $T$. maritima molecule between residues 1 and 90 . This is borne out by the fact that replacement of the first 90 amino acids of both the isolated $\mathrm{G}$ domain and the fuil-length EF-Tu with the corresponding sequence of a mesuphile (E. coli) F.F-Tu gives rise to heat-labile proteins that do not tolerate heating at tempetatures above $65^{\circ} \mathrm{C}(\mathrm{F} . \mathrm{F}-\mathrm{Tu})$ and $60^{\circ} \mathrm{C}(\mathrm{C}$ domain). (3) The $\mathrm{N}$-terminal residues involved in thermal stability defy detection, as no amino acid preferences (or unique sequence motifs) appear to distinguish the $T$. maritima EF-Tu from the corresponding E $\mathrm{L}^{\mathrm{i}}$-Tu of mesophilic and other thermophilic (Thermus thermophilus and Aquifex pyropbilus) bacteria. Regardless of which residue(s) are involved, however, thesc appear to act through interaction with distal residues of the molecule. This interpretation is suggested by the fact that hybrid proteins comprising the first 90 residues of $T$. maritima F.F-Tu and the remaining resictues of $E$. coli LF-Tu are thermally labile, as would be expected if the 1 . coli moiety lacks putative residues involved in (stabilizing) interactions with residues situated in the $T$. maritima $\mathrm{N}$-terminal portion of the molecule.

The data encourage random mutagenesis experiments focused on the initial portion of the $T$. maritima tuf gene. Combined functional and structural studies of the modified EF-Tus may cast light on the mechanism(s) that enable the thermophile factor to retain catalytic activity neat the temperature of boiling water.

\section{ACKNOWLEDGEMENTS}

This work was supported by grants from MURS'I and by a CNR grant Progetto Finalizzato Biotccnologic e Biostrumentazione, sottoprogetto Bioingegneria Molecolarc e Cellulare. 


\section{REFERENCES}

Adams, M. W. W. (1993). Enzymes and proteins from organisms that grow near and above $100^{\circ} \mathrm{C}$. Annu Rev Microbiol 47, 627-658.

Altschul, S. F., Gish, W., Miller, W., Myers, E. W. \& Lipman, D. J. (1990). Basic local alignment search tool. J Mol Biol 215, 403-410.

An, G. \& Friesen, J. D. (1980). The nucleotide sequence of $t u f B$ and four nearby tRNA structural genes of Escherichia coli. Gene 12, $33-39$.

Argos, P., Rossmann, M. G., Grau, U. M., Zuber, H., Frank, G. \& Tratschin, J. D. (1979). Thermal stability and protein structure. Biocbemistry 18, 5698-5703.

Bachleitner, M., Ludwig, W., Stetter, K. O. \& Schleifer, K. H. (1989). Nucleotide sequence of the gene coding for the elongation factor Tu from the extremely thermophilic eubacterium Thermotoga maritima. FEMS Microbiol Lett 57, 115-120.

Berchtold, H., Reshetnikova, L., Reiser, C. O. A., Schirmer, N. K., Sprinzl, M. \& Hilgenfeld, R. (1993). Crystal structure of active elongation factor 'Tu reveals major domain rearrangements. Nature $365,126-132$.

Bernardi, A. \& Bernardi, F. (1979). Construction in vitro of hybrid plasmids carrying all the EcoRI fragments from lrif ${ }^{\mathrm{d}} 18$ DNA. Eur J Biochem 95, 391-398.

Bocchetta, M., Ceccarelli, E., Creti, R., Sanangelantoni, A. M., Tiboni, O. \& Cammarano, P. (1995). Arrangement and nucleotide sequence of the gene ( $f u s$ ) encoding elongation factor $G$ (EF-G) from the hyperthermophilic bacterium Aquifex pyropbilus: phylogenetic depth of hyperthermophilic bacteria inferred from analysis of the EF-G/fus sequences. J Mol Evol 41, 803-812.

Bolivar, F., Rodriguez, R. L., Greene, P. J., Betlach, M. C., Heyneker, H. L., Boyer, H. W., Crosa, J. H. \& Falkow, S. (1977). Construction and characterization of new cloning vehicles. II. A multipurpose cloning system. Gene 2, 95-113.

Burggraf, S., Olsen, G. J., Stetter, K. O. \& Woese, C. R. (1992). A phylogenetic analysis of Aquifex pyrophilus. Syst Appl Microbiol 15, 352-356.

Buttarelli, F. R., Calogero, R. A., Tiboni, O., Gualerzi, C. O. \& Pon, C. L. (1989). Characterization of the str operon genes from Spirulina platensis and their evolutionary relationship to those of other prokaryotes, Mol Gen Genet 217, 97-104.

Dagert, M. \& Ehrlich, S. D. (1979). Prolonged incubation in calcium chloride improves the competence of Escherichia coli cells. Gene 6, 23-28.

Dever, T. E., Glynias, M. J. \& Merrick, W. C. (1987). GTP-binding domain: three consensus sequence elements with distinct spacing. Proc Nall Acad Sci US A 84, 1814-1818.

Fabry, S., Lang, J., Niermann, T., Vingron, M. \& Hensel, R. (1989). Nucleotide sequence of the glyceraldehyde-3-phosphate dehydrogenase gene from the mesophilic methanogenic archaebacteria Methanobacterium bryantii and Methanobacterium formicicum. Comparison with the respective gene structure of the closely related extreme thermophile Metbanothermus fervidus. Eur J Biocbem 179, 405-413.

Higuchi, R., Stang, H. D., Browne, J. K., Martin, M. O., Huot, M., Lipeles, J. \& Salser, W. (1981). Human ribosomal RNA gene spacer sequences are found interspersed elsewhere in the genome. Gene 15, $177-186$

Jensen, M., Cool, R. H., Mortensen, K. K., Clark, B. F. C. \& Parmeggiani, A. (1989). Structure-function relationships of elongation factor Tu. Isolation and activity of the guanine-nucleotidebinding domain. Eur J Biochem 182, 247-255.
Kjeldgaard, M. \& Nyborg, J. (1992). Refined structure of elongation factor EF-Tu from Eschericbia coli. J Mol Biol 223, 721-742.

Laemmii, U. K. (1970). Cleavage of structural proteins during the assembly of the head of bacteriophage T4. Nature 227, 680-685.

Love, D. R. \& Streiff, M. B. (1987). Molecular cloning of a $\beta$ glucosidase gene from an extremely thermophilic anaerobe in $E$. coli and B. subtilis. Biotechnology 5, 384-387.

Marck, C. (1988). 'DNA Strider': a ' $C$ ' program for the fast analysis of DNA and protein sequences on the Apple Macintosh family of computers. Nucleic Acids Res 16, 1829-1836.

Nosoh, Y. \& Sekiguchi, T. (1990). Protein engineering for thermostability. Trends Biotecbnol 8, 16-20.

Parmeggiani, A., Swart, G. W. M., Mortensen, K. K., Jensen, M., Clark, B. F. C., Dente, L. \& Cortese, R. (1987). Properties of a genetically engineered $\mathrm{G}$ domain of elongation factor Tu. Proc Natl Acad Sci US A 84, 3141-3145.

Peter, M. E., Reiser, C. O. A., Schirmer, N. K., Kiefhaber, T., Ott, G., Grillenbeck, N. W. \& Sprinzl, M. (1990). Interaction of the isolated domain II/III of Thermus thermophilus elongation factot Tu with the nucleotide exchange factor EF-Ts. Nucleic Acids Res 18, 6889-6893.

Russel, D. R. \& Bennet, G. N. (1982). Construction and analysis of in vivo activity of $E$. coli promoter hybrids and promoter mutants that alter the -35 to -10 spacing. Gene 20, 231-243.

Sanangelantoni, A. M., Forlani, G., Ambroselli, F., Cammarano, P \& Tiboni, O. (1992). The gin $A$ gene of the extremely thermophilic eubacterium Thermotoga maritima: cloning, primary structure, and expression in Escherichia coli. J Gên Microbiol 138, 383-393.

Sanger, F., Nicklen, S. \& Coulson, A. R. (1977). DNA sequencing with chain-terminating inhibitors. Proc Natl Acad Sci USA 74, 5463-5467.

Schultes, V., Deutzmann, R. \& Jaenicke, R. (1990). Complete amino-acid sequence of glyceraldehyde-3-phosphate dehydrogenase from the hyperthermophilic eubacterium Tbermotoga maritima. Eur J Biocbem 192, 25-31.

Seidler, L., Peter, M., Meissner, F. \& Sprinzl, M. (1987). Sequence and identification of the nucleotide binding site for the elongation factor Tu from Thermus thermophilus HB8. Nucleic Acids Res 15, 9263-9277.

Tiboni, O., Di Pasquale, G. \& Ciferri, O. (1978). Purification of the elongation factors present in spinach chloroplasts. Eur J Biochem 92 , 471-477.

Tiboni, O., Sanangelantoni, A. M., Cammarano, P., Cimino, L., Di Pasquale, G. \& Sora, S. (1989). Expression in Eschericbia coli of the tuf gene from the extremely thermophilic eubacterium Thermotoga maritima: purification of the Thermotoga elongation factor $\mathrm{Tu}$ by thermal denaturation of the mesophile host-cell proteins. System Appl Microbiol 12, 127-133.

Vieira, J. \& Messing, J. (1982). The pUC plasmids, an M13mp $7-$ derived system for insertion mutagenesis and sequencing with synthetic universal primers. Gene 19, 259-268.

Weijland, A., Harmark, K., Cool, R. H., Anborgh, P. H. \& Parmeggiani A. (1992). Elongation factor $\mathrm{Tu}$; a molecular switch in protein biosynthesis. Mol Microbiol 6, 683-688.

Yokota, T., Sugisaki, H., Takanami, M. \& Kaziro, Y. (1980). The nucleotide sequence of the cloned taf $A$ gene of Escherichia coli. Gene 12, 25-31.

Received 6 December 1995; revised 17 April 1996; accepted 19 April 1996. 